MRS Advances (C) 2016 Materials Research Society

DOI: $10.1557 /$ adv.2016.150

\title{
Using bacteria to make improved, nacre-inspired materials
}

\author{
Dominik T. Schmieden, Anne S. Meyer* and Marie-Eve Aubin-Tam* \\ Department of Bionanoscience, Delft University of Technology, Lorentzweg 1, 2628 CJ Delft, \\ The Netherlands
}

* Corresponding authors: A.S.Meyer@tudelft.nl, M.E.Aubin-Tam@tudelft.nl

\begin{abstract}
Nacre (mother of pearl) is an attractive model for the development of new materials. Its sheet structure of alternating layers of calcium carbonate and an organic matrix confers it highly desirable properties such as high toughness and strength. In this study, we produce a nacreinspired composite material using only bacterially-produced components. Calcium carbonate is crystallized via the action of ureolytic bacteria. After each crystallization event, we apply bacterially produced $\gamma$-polyglutamate (PGA) to the sample, which promotes layering compared to the PGA-free control. We show that the combination of these two compounds yields a layered material reminiscent of nacre, showing a way towards the biotechnological production of new, nacre-inspired materials.
\end{abstract}

\section{INTRODUCTION}

Mollusks have developed hard shells as protection against predators. The inner layer of many of these shells is nacre (mother of pearl), a composite material consisting of layers of aragonite (calcium carbonate) platelets interconnected by a complex organic matrix (Figure 1). The calcium carbonate layers have in many cases a thickness of $0.3-0.5 \mu \mathrm{m}$, depending on the animal species, while the organic matrix reaches only 20-30 nm [1]. Even though nacre consists of $95 \%$ calcium carbonate, its mechanical properties differ dramatically from monolithic calcium carbonate, e. g. with a much higher fracture toughness and strength (reviewed in [2]). These highly desirable mechanical properties have inspired a great deal of research into the production of nacre-like composite materials (reviewed in $[3,4]$ ), using techniques ranging from freeze-casting [5] to self-assembly of nanoclays [6]. In this study, we aim at laying the foundation for producing nacre-inspired composite materials with the aid of bacteria. Bacteria offer a wide range of metabolic products, are readily accessible to genetic engineering, and are efficient and environmentally-friendly tools for the production of various compounds. For the production of nacre-like compounds, at least two building blocks are required: calcium carbonate layers and a connecting matrix.

Bacteria have been associated with carbonate deposition in diverse habitats including sea water, saline lakes, soils, and geological formations [7]. One mechanism of bacterially-induced calcium carbonate formation is the breakdown of urea by ureolytic bacteria such as Sporosarcina pasteurii. The ensuing formation of ammonia and carbonate increases the ambient $\mathrm{pH}$, causing calcium to fall out of solution as crystalline calcium carbonate. The use of $S$. pasteurii to produce calcium carbonate has been demonstrated in laboratory settings for applications such as soil improvement and biogrouting [8,9] or repair of cracks in concrete [10]. This ureolytic activity can be transferred into the model organism Escherichia coli by genetic engineering [11], making it an attractive candidate for synthetic biology projects. 


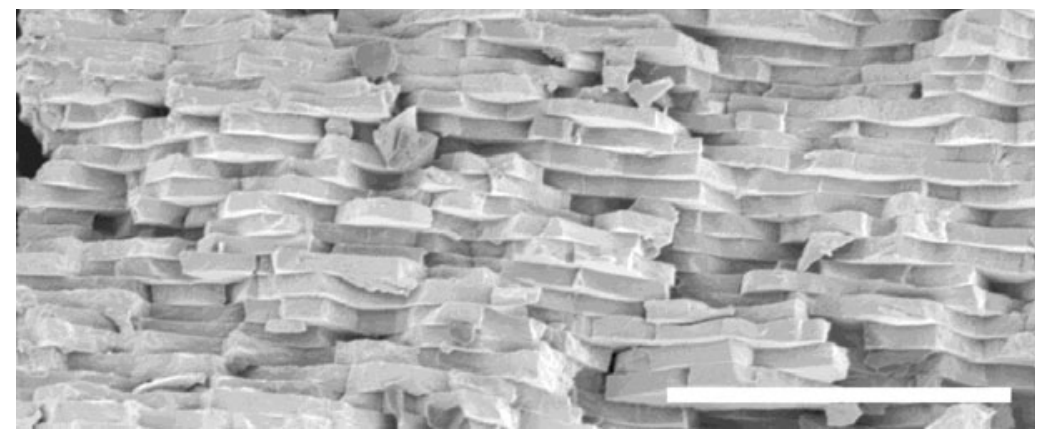

Figure 1 SEM picture of blue mussel (Mytilus edulis) nacre. Scale bar is $20 \mu \mathrm{m}$.

$\gamma$-Polyglutamate (PGA) is an exo-polymer produced by many members of the Bacillus genus that serves e. g. as protection against the immune system [12]. Thanks to its unusual $\gamma-$ linkage, it is resistant to proteases [13]. PGA has evoked considerable interest in industrial applications, as it is non-toxic, non-immunogenic, biodegradable, edible, and water soluble [14]. Cationic polymeric substances such as polyaspartate have been demonstrated to promote the formation of calcium carbonate thin films on a chitosan substrate, where their negatively charged carboxyl groups serve as binding sites for calcium ions [15]. In this study, we employ $\gamma$-PGA as a mimic for the organic matrix of nacre, expecting that $\gamma$-PGA might show a calcium carbonate templating function similar to polyaspartate, while being easy to produce from natural producers or transgenic organisms $[16,17]$.

The aim of this study is to investigate whether the combination of calcium carbonate and PGA can produce a layered, nacre-like material, which would open the door for the development of transgenic microorganisms for the production of new composite materials in an easy and environmentally friendly manner.

\section{EXPERIMENT}

Chemicals were purchased from VWR Netherlands or Sigma Aldrich Netherlands unless otherwise indicated. Bacterial cultures were grown in rotary shakers with temperature control at $180 \mathrm{rpm}$ unless otherwise indicated.

\section{$\underline{\text { Substrate preparation }}$}

Microscope slides (Corning 2947, 75x25x1 mm) were used as substrates for material deposition. Since calcium carbonate does not crystallize as a film on glass, the slides were covered with a calcium carbonate thin film as in [15] for the first crystallization event. A solution of $1 \mathrm{wt} \%$ chitosan (Sigma 448877, medium mol. weight, $75-85 \%$ deacetylation) in $1 \mathrm{v} / \mathrm{v} \%$ acetic acid was spin-coated on the microscope slides, dried for $10-30 \mathrm{~min}$ at $60^{\circ} \mathrm{C}$, neutralized with $0.1 \mathrm{wt} \% \mathrm{NaOH}$ solution, rinsed with MilliQ water, and air-dried with a flow of nitrogen gas. The slide was then placed downwards-facing, on two magnetic stirrer bars as supports, into a Petri dish containing a solution of $30 \mathrm{mM} \mathrm{CaCl}_{2}, 90 \mathrm{mM} \mathrm{MgCl}_{2}$, and $0.005 \mathrm{wt} \%$ polyacrylic acid (avg. 
$\mathrm{Mw} \sim 2100 \mathrm{~g} / \mathrm{mol})$. The dish and a beaker containing $50 \mathrm{~g}\left(\mathrm{NH}_{4}\right) \mathrm{HCO}_{3}$ were placed in a $5 \mathrm{~L}$ closed desiccator and incubated for 3 days at room temperature, allowing a thin film of calcium carbonate to form on the chitosan. Afterwards, the slide was removed from the solution, rinsed with MilliQ water, dried with a flow of nitrogen gas, and used as a substrate for the subsequent crystallization experiments.

\section{PGA production and isolation}

Bacillus licheniformis NBRC12107 (ATCC 9945a) was purchased from the Biological Resource Center, National Institute of Technology and Evaluation (Japan) and cultured in BLmedium $\left(10 \mathrm{~g} / \mathrm{L}\right.$ peptone, $2 \mathrm{~g} / \mathrm{L}$ yeast extract, $1 \mathrm{~g} / \mathrm{L} \mathrm{MgSO}_{4} * 7 \mathrm{H}_{2} \mathrm{O}$, sterilized by autoclaving) overnight at $30^{\circ} \mathrm{C}$ for starter cultures and glycerol stock cultures.

For production of PGA, Medium E [18] (20 g/L L-glutamic acid, $13.6 \mathrm{~g} / \mathrm{L}$ monosodium citrate, $80 \mathrm{~g} / \mathrm{L}$ glycerol, $7 \mathrm{~g} / \mathrm{L} \mathrm{NH}_{4} \mathrm{Cl}, 0.5 \mathrm{~g} / \mathrm{L} \mathrm{KH}_{2} \mathrm{PO}_{4}, 0.244 \mathrm{~g} / \mathrm{L} \mathrm{MgSO}_{4}, 0.04 \mathrm{~g} / \mathrm{L}$ $\mathrm{FeCl}_{3} * 6 \mathrm{H}_{2} \mathrm{O}, 0.15 \mathrm{~g} / \mathrm{L} \mathrm{CaCl}_{2} * 2 \mathrm{H}_{2} \mathrm{O}, 0.1 \mathrm{~g} / \mathrm{L} \mathrm{MnSO}_{4} * \mathrm{H}_{2} \mathrm{O}, \mathrm{pH} 7.5$ with $\mathrm{NaOH}$, sterilized by autoclaving) was inoculated with $1.5 \%$ starter culture and cultured at $30^{\circ} \mathrm{C}$ for around 2 days until formation of a viscous fluid. The following steps were performed at $4-8^{\circ} \mathrm{C}$ wherever possible. The bacteria culture was centrifuged for $30 \mathrm{~min}$ at $8200 \mathrm{~g}$, and PGA was precipitated from the supernatant by addition of 0.3-0.4 $\mathrm{M} \mathrm{CuSO}_{4}[19]$. The solution was centrifuged for $10 \mathrm{~min}$ at $8200 \mathrm{~g}$ and the sediment re-dissolved in $0.5 \mathrm{M}$ EDTA ( $\mathrm{pH} 8$ with $\mathrm{NaOH}$ ). CopperEDTA complexes were removed by dialysis with Spectra/Por 2 Dialysis Tubing, 12-14 kD MWCO (Spectrum Europe B.V., The Netherlands) against MilliQ water. The dialyzed PGA solution was centrifuged for $20 \mathrm{~min}$ at $8200 \mathrm{~g}$ to remove any solid residue, frozen at $-20^{\circ} \mathrm{C}$, and freeze-dried. The resulting PGA crystals were ground, dissolved in MilliQ water $(8 \mathrm{~g} / \mathrm{L}, \mathrm{pH} 13$ with $\mathrm{NaOH}$ ) and frozen until use.

\section{Crystallization experiments}

Sporosarcina pasteurii DSM-33 (ATCC 11859) was purchased from the Leibniz Institute DSMZ (Germany) and cultured in SP2-medium $(20 \mathrm{~g} / \mathrm{L}$ yeast extract, $10 \mathrm{~g} / \mathrm{L} \mathrm{NH} 4 \mathrm{Cl}, 10 \mu \mathrm{M}$ $\mathrm{NiCl}_{2}, \mathrm{pH} 8.5$ with $\mathrm{NaOH}$, sterilized by autoclaving) [9]. This medium was used for generation of glycerol stocks $(20 \mathrm{wt} \%)$ and starter cultures for crystallization experiments. For the latter, S. pasteurii was cultured for 2 days at $28^{\circ} \mathrm{C}$. The culture was then concentrated $10 \mathrm{X}$ by centrifugation for $15 \mathrm{~min}$ at $1500 \mathrm{~g}$ and mixed $1: 1$ with sterile $40 \mathrm{wt} \%$ glycerol. Aliquots were stored at $-80^{\circ} \mathrm{C}$ until use.

Crystallization experiments were performed by placing a glass slide covered with a $\mathrm{CaCO}_{3}$ thin film, facing downwards, on magnetic stirrer bars as supports, in an $800 \mathrm{~mL}$ glass beaker. The beaker was then filled with $100 \mathrm{~mL}$ crystallization medium $(10 \mathrm{~g} / \mathrm{L}$ tryptone, $5 \mathrm{~g} / \mathrm{L}$ yeast extract, $10 \mathrm{~g} / \mathrm{L} \mathrm{NH}_{4} \mathrm{Cl}, 60 \mathrm{mM} \mathrm{CaCl}_{2}, 20 \mathrm{~g} / \mathrm{L}$ urea, sterilized by autoclaving except urea, which was filter-sterilized) and inoculated with $100 \mu \mathrm{L} S$. pasteurii starter culture. After incubation overnight at $28^{\circ} \mathrm{C}$ without shaking, the glass slide was removed, rinsed with MilliQ water, and air-dried. For experiments with PGA, the slide was then covered with PGA solution $(0.5 \mathrm{mg}$ $\mathrm{PGA} / \mathrm{cm}^{2}$ ) and dried with a hot air gun (Limitless LS-H2000, $2000 \mathrm{~W}$ ). Crystallization of $\mathrm{CaCO}_{3}$ and application of PGA (where applicable) were repeated 23 times, the first two PGA applications were omitted to provide a better substrate for $\mathrm{CaCO}_{3}$ deposition on the slides. 


\section{Electron Microscopy and layering estimate}

Before imaging by scanning electron microscopy (SEM), samples were fractured manually and covered with a $10 \mathrm{~nm}$ gold film using a Leica EM ACE 60 sputter coater. SEM was performed with a FEI Nova Nano SEM 450, using a beam acceleration of $3 \mathrm{kV}$. To estimate the extent of layering in a sample, entire cross-sections were imaged, and the width of the layered structures measured.

Mytilus edulis shells were prepared similarly but fractured with a hammer prior to imaging.

\section{RESULTS AND DISCUSSION}
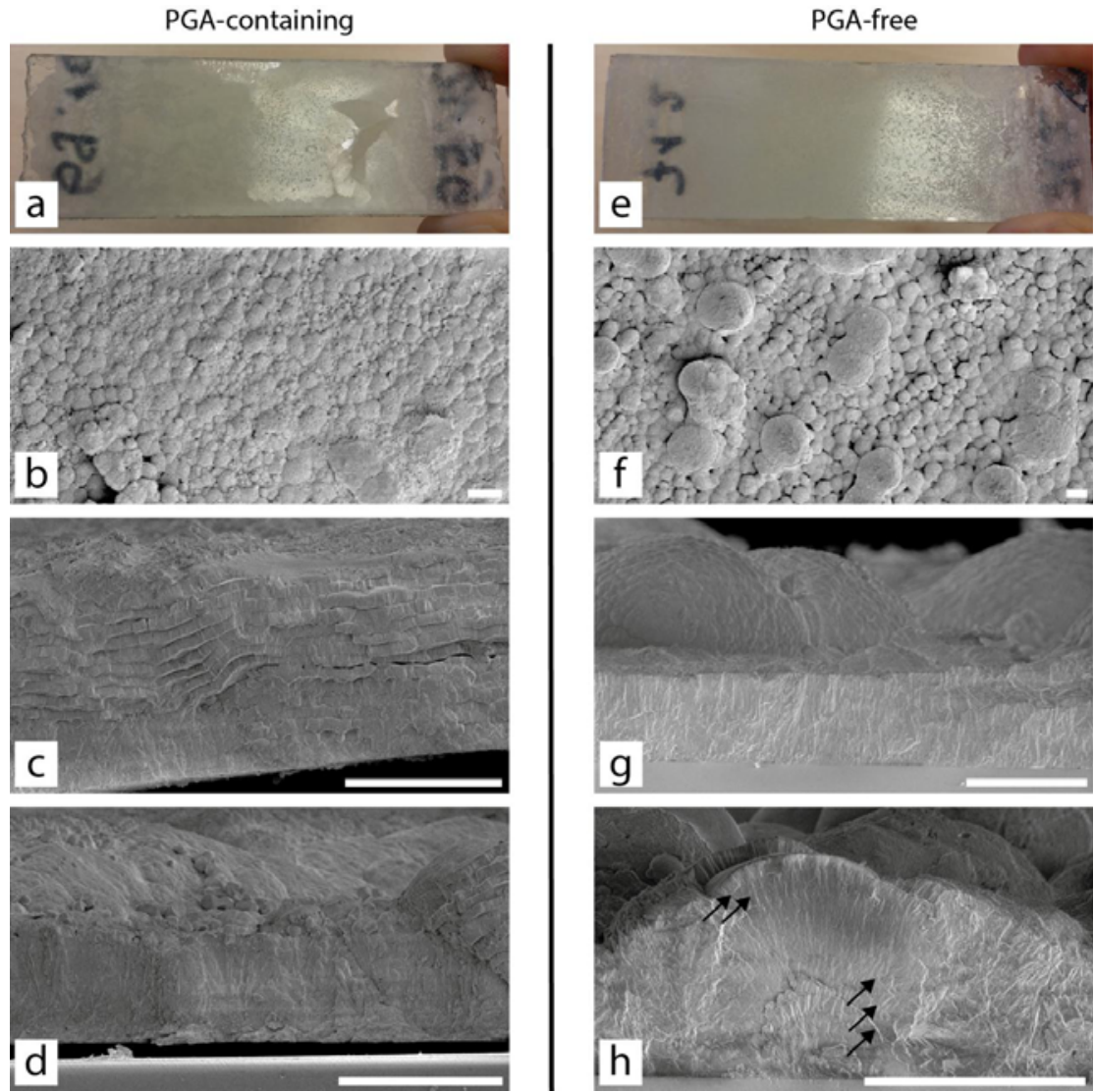

Figure 2 a-d: Glass slides covered with $\mathrm{CaCO}_{3}$, crystallized 23 times on the slide via the action of ureolytic $S$. pasteurii. After each crystallization event, $0.5 \mathrm{mg} / \mathrm{cm}^{2}$ PGA was dried on the slide e-h: Samples prepared as in a-d, but without PGA application a, e: Macroscopic view after 
polishing b, f: SEM pictures of top views $\mathbf{c}, \mathbf{d}, \mathbf{g}, \mathbf{h}$ : SEM pictures of cross-sections, $\mathbf{c}$ and $\mathbf{h}$ showing layered, $\mathbf{d}$ and $\mathbf{g}$ showing un-layered areas. All scale bars are $100 \mu \mathrm{m}$; boundaries between individual layers are marked with arrows in panel $\mathbf{h}$.

The aim of this study was to generate a nacre-inspired compound material using only bacterially-produced materials. To achieve this, we subjected glass slides to 23 calcium carbonate crystallization cycles by $S$. pasteurii. After each crystallization cycle, a subset of slides was coated with $0.5 \mathrm{mg} / \mathrm{cm}^{2}$ of microbially-produced PGA. The other set of samples received no PGA between calcium carbonate crystallization events, serving as a negative control.

Various features of PGA-containing samples were analyzed. Macroscopic investigation showed that the slides were densely covered with deposited material (Figure 2 a). Cavities were observed under large areas of the material, leading to detachment of flakes. Scanning electron microscopy (SEM) of top views (Figure $2 \mathrm{~b}$ ) revealed a seemingly random arrangement of crystals of different morphologies, suggesting the presence of primarily spherical vaterite, but also rhombohedral calcite and vaterite-calcite intermediates.

SEM images of cross-sections of the PGA-containing material showed layered structures in about $40 \%$ of the cross-sectional area, either forming a relatively flat, layered sheet on the substrate, or as internal structures of spherical crystals (Figure $2 \mathrm{c}$ ). Layers were observed mostly at the edges of the slide. Here, also the overall material thickness was highest. The central regions of the slide showed a base layer of calcium carbonate with crystals of various shapes protruding from it (Figure $2 \mathrm{~d}$ ). When layering occurred here, it was restricted to spherical crystals. No organic material could be detected between layers of calcium carbonate, thus any layer of PGA would have a thickness of below $50 \mathrm{~nm}$.

PGA-free samples showed an altered morphology. Macroscopically, we observed good coverage of calcium carbonate that was strongly bound to the surface, though with some rough areas with inhomogeneous coverage in the center of the slide (Figure $2 \mathrm{e}$ ). As in PGA-containing samples, the main crystal morphology was spherical vaterite (Figure $2 \mathrm{f}$ ). SEM on cross-sections of the samples showed either single crystals or, as in the central region of PGA-containing samples, a base layer of calcium carbonate with crystals protruding from it (Figure $2 \mathrm{~g}$ ). This base layer generally did not contain obvious internal structures, but regions of spherical crystals often had an inner structure that contained 3-10 layers (Figure $2 \mathrm{~h}$ ). Layers stretched over a much smaller overall width of the cross-section than in PGA-containing samples (Table I) and were absent in regions outside of spherical crystals.

Table I Estimated proportion of layered structures in cross-sections of four samples

\begin{tabular}{ll}
\hline Sample & Layered \\
\hline PGA-free 1 & $10 \%$ \\
\hline PGA-free 2 & $8 \%$ \\
\hline PGA containing 1 & $37 \%$ \\
\hline PGA containing 2 & $42 \%$ \\
\hline
\end{tabular}


Layers in PGA-containing samples had an average thickness of $6 \pm 1 \mu \mathrm{m}$ (SD), while layers in PGA-free samples were $8 \pm 1 \mu \mathrm{m}$ thick. These layers are 5-20 times thicker than calcium carbonate layers in nacre, which have a typical thickness of $0.3-0.5 \mu \mathrm{m}$ [1]. These thicker layers may result in a lower fracture strength in comparison to natural nacre [20].

\section{CONCLUSIONS}

We have shown that PGA promotes formation of layers in experiments with repeated crystallization of calcium carbonate, allowing the production of a layered composite material exclusively made with bacterial products. This research could lead to the development of new, biotechnologically produced, nacre-like materials with potential applications in engineering or medicine.

\section{ACKNOWLEDGMENTS}

This work was supported by the Netherlands Organization for Scientific Research (NWO/OCW).

\section{REFERENCES}

1. M. A. Meyers, P.-Y. Chen, A. Y.-M. Lin, and Y. Seki, Prog. Mater. Sci. 53 (1), 1 (2008).

2. J. Sun and B. Bhushan, RSC Adv. 2 (20), 7617 (2012).

3. J. Wang, Q. Cheng, and Z. Tang, Chem. Soc. Rev. 41 (3), 1111 (2012).

4. I. Corni, T. J. Harvey, J. A. Wharton, K. R. Stokes, F. C. Walsh, and R. J. K. Wood, Bioinspiration Biomimetics 7 (3), 31001 (2012).

5. S. Deville, E. Saiz, R. K. Nalla, and A. P. Tomsia, Science 311 (5760), 515 (2006).

6. P. Das, J.-M. Malho, K. Rahimi, F. H. Schacher, B. Wang, D. E. Demco, and A. Walther, Nat. Commun. 6 (2015).

7. F. Hammes and W. Verstraete, Rev. Environ. Sci. Biotechnol. 1 (1), 3-7 (2002).

8. M. P. Harkes, L. A. van Paassen, and V. S. Whiffin, Geomicrobiol. J. 24 (5), 417 (2007).

9. L. A. van Paassen, R. Ghose, T. van der Linden, W. van der Star, and M. van Loosdrecht, J. Geotech. Geoenviron. Eng. 136 (12), 1721 (2010).

10. S. S. Bang, J. K. Galinat, and V. Ramakrishnan, Enzyme Microb. Technol. 28 (4-5), 404 (2001).

11. K. L. Bachmeier, A. E. Williams, J. R. Warmington, and S. S. Bang, J. Biotechnol. 93 (2), 171 (2002).

12. S. Makino, I. Uchida, N. Terakado, C. Sasakawa, and M. Yoshikawa, J. Bacteriol. 171 (2), 722 (1989).

13. F. B. Oppermann-Sanio and A. Steinbüchel, Naturwissenschaften 89 (1), 11-22 (2002).

14. J. M. Buescher and A. Margaritis, Crit. Rev. Biotechnol. 27 (1), 1 (2007).

15. A. Sugawara and T. Kato, Chem. Commun. (6), 487 (2000).

16. H. Jiang, L. Shang, S. Yoon, S. Lee, and Z. Yu, Biotechnol. Lett. 28 (16), 1241-1246 (2006).

17. M. Ashiuchi, K. Soda, and H. Misono, Biochem. Biophys. Res. Commun. 263 (1), 6 (1999).

18. G. Kedia, D. Hill, R. Hill, and I. Radecka, J. Nanosci. Nanotechnol. 10 (9), 5926 (2010).

19. B. Manocha and A. Margaritis, Biotechnol. Prog. 26 (3), 734 (2010).

20. H. Gao, B. Ji, I. L. Jäger, E. Arzt, and P. Fratzl, PNAS 100 (10), 5597 (2003). 